\title{
BORGES E A INFÂMIA DE TODOS NÓS
}

Julio Jeha

UFMG

\begin{abstract}
RES U M O
Em História universal da infâmia, Borges narra contos enganadoramente simples, sobre protagonistas aventureiros e criminosos de várias formas, sobre crime e vilania. Misturando fato e ficção, quase sempre com reverberação mítica, deu aos contos uma impressão de autenticidade surrealista. Ao lançar mão de recursos mitopoéticos, Borges apresenta a infâmia, senão como força universal, pelo menos como um traço constituinte da natureza humana. Com a narrativa literária, ele nos permite ver mal e sofrimento como resultado, ainda que parcial, de ações inter-humanas e arranjos sociais.
\end{abstract}

\section{PALAVRAS - CHAVE}

Borges. Infâmia. Mal.

A partir dos seus primeiros textos publicados na revista Crítica entre 1933 e 1934, Jorge Luis Borges já mostrava interesse pela infâmia, um interesse que perpassaria toda a sua obra. Coligiu sete desses contos em um volume, História universal da infâmia (1935), como um exercício narrativo sobre personagens reais ou fictícias que adquiriram má reputação por seus atos torpes, acontecidos ou imaginados. Com o título da coletânea, o autor rejeitava a explicação do mal por fatores espaciotemporais, por injustiças socioeconômicas, maus-tratos, ou quaisquer outros fatores externos à natureza humana.

O mal, segundo a tradição latina, é uma limitação que impede um ente de alcançar uma perfeição que de outra maneira seria possível para aquele ente. Para os seres humanos, esse movimento se dá, quase sempre, em comunidade, na relação do eu com o outro. Essa relação deve se traduzir numa boa convivência garantida por instituições justas, isto é, numa perspectiva ética. ${ }^{1}$ Como efeito do mal, perde-se de vista uma interpretação final - ainda que apenas potencial - que una e transcenda os seres humanos. ${ }^{2}$ Em outras palavras, o mal interrompe o movimento teleológico dos seres humanos, criando obstáculos à sua compreensão do mundo e à sua plenitude.

A definição latina tem o mérito de ser ampla e simples o bastante para cobrir uma multidão de pecados, mas, para os propósitos deste trabalho, carece de algumas restrições. O mal que nos interessa é o causado pelos humanos e não catástrofes e defeitos

\footnotetext{
${ }^{1}$ RICCEUR. Em torno do político, p. 163.

${ }^{2}$ RICCEUR. O mal: um desafio à filosofia e à teologia.
} 
congênitos, por exemplo. Isso, porém, não significa que a capacidade de cometer o mal não seja uma característica natural, inata ao ser humano. O mal será abordado como um processo de criar sofrimento e infelicidade desnecessários, de transgredir as leis e pisotear os valores humanos.

Paul Ricœur, ao distinguir entre pecado, sofrimento e morte, divide o mal em duas categorias: "a da culpa e a do lamento", correspondentes a mal cometido e a mal sofrido. ${ }^{3}$ Quando infringimos um código de conduta vigente e essa infração é passível de punição, falamos em culpa. Quando sofremos pela perda de alguém que amamos ou por contrair alguma doença ou por um desastre qualquer, lamentamos que isso tenha ocorrido a nós. Culpa e lamento se opõem: aquela nos revela como malfeitores; este, como vítimas. Eis aqui a conexão intrínseca entre os dois termos: cometer o mal consiste em fazer o outro sofrer.

Em História universal da infâmia, Borges narra contos aparentemente simples, sobre protagonistas aventureiros e criminosos de várias formas, sobre crime e vilania, que permanecerão constantes em sua ficção. Com os sete relatos desse volume, o autor argentino inicia uma técnica narrativa da qual foi mestre: o uso de fontes e referências apócrifas, em detrimento da ficção mais longa, que ele considerava tão entediante quanto a própria vida. Misturando fato e ficção, quase sempre com tons míticos, deu aos contos uma aparência de autenticidade surrealista. Ao lançar mão de recursos mitopoéticos, Borges apresenta a infâmia, senão como força universal, pelo menos como um traço constituinte da natureza humana. Com a narrativa literária, por outro lado, ele nos permite ver mal e sofrimento, ainda que parcialmente, como resultado de ações inter-humanas e arranjos sociais.

O presente trabalho irá a contrapelo das duas linhas dominantes na crítica borgesiana: de um lado, aqueles que interpretam suas tendências metafísicas como escapismo (Eduardo Galeano, por exemplo); de outro, aqueles que buscam corrigir os primeiros, enxergando em Borges um desejo pelas origens, uma busca pelo terreno estável da história (tais como Ricardo Piglia e Beatriz Sarlo). Os textos do autor argentino podem ser lidos como um questionamento de categorias, reconhecendo as lições da metafísica para criticar historicismos e sociologismos ingênuos que não concebem a possibilidade de uma natureza humana capaz de infâmias e vilanias, a não ser por força de condições socioeconômicas determinantes.

Cada um dos contos em História universal da infâmia permite ao leitor entrever o mal que homens e mulheres cometem. Eles cobrem todo o globo: vão dos estados escravocratas no Sul dos Estados Unidos antes da Guerra Civil, em "O estranho redentor Lazarus Morell", aos mares da China no século 19, em "A viúva Ching, pirata”, ao Japão feudal, em "O descortês mestre-de-cerimônias Kotsuké no Suké", à Nova York no início do século 20, em "O provedor de iniquidades Monk Eastman", ao Turcomenistão, em "O tintureiro mascarado Hákim de Merv". Essas histórias foram parcialmente baseadas em tratados históricos pouco conhecidos, em As mil e uma noites e outros textos de ficção. Ainda que o título da coletânea sugira uma empreitada totalizante, a criação de

${ }^{3}$ RICCEUR. O mal: um desafio à filosofia e à teologia, p. 23. 
uma enciclopédia da infâmia, "Borges não descarta o indivíduo em favor da espécie". ${ }^{4}$ Muitos críticos o condenam por negar a realidade da experiência humana, mas isso está longe de ser verdade. As suas personagens se definem não em termos de sociedade, história ou outros fatores externos, mas sim pelo que ocorre em suas vidas.

Para Borges, tentamos resistir ao caos que nos ameaça por meio de uma organização do conhecimento, de uma ordenação do mundo, que, embora desejável, é destinada ao fracasso, pois a existência humana se caracteriza pela fragmentação, pela ruptura da ordem, pela negação, enfim, da Lei. Tentar classificar ou catalogar o universo, escreve ele em "El idioma analítico de John Wilkins", é exercer o caos. Tal desorganização aparece nos seus textos, que se opõem com tenacidade a leituras modeladoras. Buscar estabelecer um padrão em Borges, assim como em Kafka, Beckett ou Nabokov, resulta em nada mais que "rupturas domesticadas". ${ }^{5}$ Assim, a ruptura da Lei vai ser a chave de leitura das biografias infames que compõem o livro em análise.

A infâmia, ou ignomínia, resulta de um ato cometido contra o que se define como o bem. Essa má reputação, duradoura, conhecida e entranhada, fruto de uma ação criminosa, chocante ou brutal, pode ser merecida ou atribuída, ocasionando em ambos os casos o mais alto grau de desonra, punida com a repulsa do grupo e a subsequente exclusão do convívio social. Testemunho disso dá Oscar Wilde em "De profundis": "Passei não da obscuridade à momentânea notoriedade do crime, mas de um tipo de fama para um tipo de eternidade de infâmia." $\mathrm{A}$ infâmia configura-se uma forma de monstruosidade moral, uma das possíveis manifestações do mal na experiência humana.

$\mathrm{Na}$ coletânea de Borges, ela advém de atos criminosos, chocantes ou brutais extremos e de conhecimento público. Nos dois primeiros contos, "O estranho redentor Lazarus Morell" e "O incrível impostor Tom Castro", assim como no último, "O tintureiro mascarado Hákim de Merv", o embuste traz a notoriedade. Mas enquanto Tom Castro usa artimanhas em benefício próprio, Lazarus Morell e Hákim de Merv cometem imposturas de consequências fatais para os que neles acreditam. Os três protagonistas têm em comum a capacidade de obter a confiança das pessoas por meio de mentiras as mais improváveis, prometendo aliviar-lhes o sofrimento.

De origem humilde mas ambicioso, Morell começou sua carreira ignóbil nos púlpitos, de onde discursava com "invulgar convicção", enquanto seus companheiros roubavam todos os cavalos da plateia. Esse duplo delito apenas prefigurava torpezas maiores. Morell dava ordens para seus homens escolherem um escravo e the proporem liberdade: que fugisse, para ser vendido por eles, que lhe dariam uma percentagem da venda e o ajudariam a uma nova escapada. Ao fugir a segunda vez, recebia uma conta de despesas obscuras e se submetia à segunda venda, com promessa de percentagem das duas negociações. Para evitar que o escravo denunciasse a perversa manobra, o "cruel redentor" mandava matá-lo e jogá-lo no rio Mississipi. Ao manejar esperança dos escravos de forma fatal, Morell garantiu um lugar na galeria dos vilões.

\footnotetext{
${ }^{4}$ AGHEANA. The Meaning of Experience in the Prose of Jorge Luis Borges, p. 35.

${ }^{5}$ MOLLOY. Las letras de Borges y otros ensayos, p. 15.

${ }^{6}$ WILDE. De profundis, p. 917. (Tradução minha)
} 
De "sossegada idiotia", Arthur Orton tomou o nome de Tom Castro ao perambular pelas cidades do Chile. Mais tarde, na Austrália, encontra Bogle, "um negro criado" dotado de genialidade. Desse encontro fortuito nasce uma dupla de falsários que, ao ler um anúncio fúnebre num jornal, aplicam um golpe desumano. Orientado por Bogle, Tom Castro se faz passar por um jovem inglês aristocrata, completamente diferente de si, e engana a mãe, que se recusa a acreditar na morte do filho num naufrágio. Como o perverso Lazarus Morell, Tom Castro manipula a esperança para benefício próprio, sem se importar com o sofrimento da vítima.

Hákim de Merv, no conto que encerra o livro, era tintureiro ("arte de ímpios, de falsários e de inconstantes”) e se fez passar por profeta de Maomé. Escondia a face atrás de uma máscara de ouro, dizendo que era resplendente por ter visto o Criador e, por isso, cegava quem a via. Criou uma religião de cosmogonia gnóstica, pela qual o céu é regido por uma divindade que não passa de "sombra de sombras de outras sombras" e a terra que habitamos é "uma incompetente paródia". Rebelando-se contra o califa e usando o Islã como base para seu culto particular, o tintureiro mascarado se torna subversivo e herege, mas não em busca de um bem social ou uma verdade espiritual; queria mesmo era o poder, que exercia por meio da população que enviava para ser massacrada pelo exército do califa. De maneira semelhante aos protagonistas das histórias anteriores, Hákim de Merv pratica atrocidades em proveito próprio, usando as pessoas como meios para atingir seu fim, cometendo o que Imannuel Kant (1974) denomina "mal radical".

Se nessas histórias os atos infames cometidos pelos protagonistas têm em comum o embuste, nas outras quatro predomina a relação ilusória entre fama e honra, entre infâmia e desonra. Em "A viúva Ching, pirata", a personagem principal se torna pirata sanguinária e temida para vingar o marido duplamente traído. Chefe de mil e duzentos homens em "O provedor de iniquidades Monk Eastman", Edward Ostermann, que anglicizou seu nome para Eastman, usa métodos atrozes para manter a ordem nos salões públicos nova-iorquinos. Preso, sai da cadeia e se alista para lutar na Primeira Guerra Mundial, em que se destaca por sua bravura. Bill Harrigan, o lendário e admirado Billy the Kid, mata 21 pessoas, "sem contar mexicanos", que odeia tanto quanto detesta os negros. Morre com um balaço desferido por seu amigo, que se tornara xerife. No conto "O descortês mestre-de-cerimônias Kotsuké no Suké", para vingar a morte do seu senhor causada pelo mestre-de-cerimônias, um samurai simula atos infames e se desonra. Após a vingança, o samurai e seus companheiros se tornam heróis. Nessas histórias, fama e ignomínia se apresentam como arremedo uma da outra, num jogo de máscaras e simulações que dificulta desvelar a motivação e a natureza das personagens.

Os atos infames nesses sete contos de Borges têm origem tanto psicológica quanto social: a personagem perversa herda uma história singular (a de sua família) e uma coletiva (a do seu grupo social). O indivíduo pode se rebelar, superar ou sublimar a perversão; ou pode se voltar para o crime, a autodestruição etc. ${ }^{7}$ A filosofia política veiculada pelo autor parece ser a de que os seres humanos estão enredados numa teia

${ }^{7}$ Cf. ROUDINESCO. A parte obscura de nós mesmos: uma história dos perversos, p. 103. 
de causas e efeitos, determinados mas sem saber o que determina as inúmeras causas. A cada escolha corresponde uma consequência, num universo caracterizado não pelo caos, mas pela estrutura labiríntica de milhares de causas embaralhadas.

\title{
A
}

\begin{abstract}
A B STRACT
In Universal History of Infamy, Borges narrates tales that are deceptively simple about adventurers and criminals in many shapes, about crime and villainy. Mixing fact and fiction, usually with mythic reverberation, he gave the tales an atmosphere of surreal authenticity. By using mythopoeic resources, Borges presents infamy if not as a universal power at least as a constitutive trait of human nature. With the literary narrative, he enables us to see evil and suffering as resulting, even if partially, from human interaction and social arrangements.
\end{abstract}

\section{KEYWORDS}

Borges. Infamy. Evil.

\section{REFERÊNCIAS}

AGHEANA, Ian T. The Meaning of Experience in the Prose of Jorge Luis Borges. New York: Peter Lang, 1988.

BORGES, Jorge Luis. El idioma analítico de John Wilkins. In: BORGES, Jorge Luis. Otras inquisiciones. Buenos Aires: Emecé, 1974. p. 84-87.

BORGES, Jorge Luis. História universal da infâmia. Trad. Flávio José Cardozo. Porto Alegre: Globo, 1986. [1935, 1954]

DE MAN, Paul. A Modern Master: Jorge Luís Borges. In: . Critical Writings, 1953-1978. Ed. Lindsay Waters. Minneapolis: The University of Minnesota Press, 1989. p. 123-129. [1964]

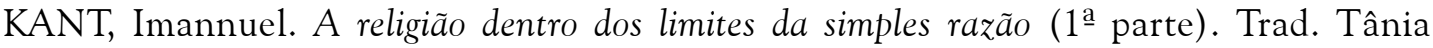
M. Bernkopf. São Paulo: Abril Cultural, 1974. (Os Pensadores)

MOLLOY, Sylvia. Las letras de Borges y otros ensayos. Rosario: Beatriz Viterbo Ed., 1999.

RICCEUR, Paul. Em torno do político. São Paulo: Loyola, 1995.

RICCEUR, Paul. O mal: um desafio à filosofia e à teologia. Campinas: Papirus, 1988.

ROUDINESCO, Elisabeth. A parte obscura de nós mesmos: uma história dos perversos. Trad. André Telles. Rio de Janeiro: Zahar, 2007.

WILDE, Oscar. De profundis. In: . Complete Works of Oscar Wilde. Introd. Vyvyan Holland. New York: Perennial Library, 1989. p. 873-957. 